\section{L'Actualité économique}

L'ACTUALITÉ ÉCONOMIQUE

\section{Index des auteurs d'articles et des titres} Cinquante-cinquième année, numéros 1 à 4

Volume 55, numéro 4, octobre-décembre 1979

URI : https://id.erudit.org/iderudit/800855ar

DOI : https://doi.org/10.7202/800855ar

Aller au sommaire du numéro

Éditeur(s)

HEC Montréal

ISSN

0001-771X (imprimé)

1710-3991 (numérique)

Découvrir la revue

Citer cet article

(1979). Index des auteurs d'articles et des titres : cinquante-cinquième année, numéros 1 à 4. L'Actualité économique, 55(4), 612-614.

https://doi.org/10.7202/800855ar d'utilisation que vous pouvez consulter en ligne.

https://apropos.erudit.org/fr/usagers/politique-dutilisation/ 


\title{
INDEX DES AUTEURS D'ARTICLES ET DES TITRES
}

\author{
(GinguANTE-GinQUième ANNÉE, NUMÉRos 1 À 4 )
}

Abgrall, Jean-François ; Roy, Pauline :

Mesure de l'efficacité des entreprises artisanales de pêche $\ldots \ldots \ldots \quad 82$

Ahmad, Jaleel :

Diversion et création d'échanges commerciaux dans le cadre du système canadien de préférences tarifaires $\ldots . \ldots \ldots \ldots \ldots$.

ARGHER, ANDRÉ :

Fonctions de production agricole au Québec

Aubry, Jean-Pierre ; Fleurent, Diane :

Simulations d'un modèle basé sur l'hypothèse du cycle de vie ....

Boughard, Gérard ; Pouyez, Ghristian ; Roy, Raymond :

Le classement des professions par secteurs d'activité : aperçu critique et présentation d'une nouvelle grille $\ldots \ldots \ldots \ldots \ldots \ldots$.

Boyer, Marcel ; Kihlstrom, Richard ; Laffont, Jean-Jacques :

Le calcul économique de la publicité frauduleuse $\ldots . . \ldots \ldots$.

Bronsard, Gamille ; Salvas-Bronsard, Lise :

Sur l'estimation d'un système complet de demande sous rationnements quantitatifs

Gameron, Duncan ; Saint-Germain, Maurice :

Vers un nouvel équilibre monétaire international : un colloque du $46^{e}$ congrès de l'AGFAS $\ldots \ldots \ldots \ldots \ldots \ldots \ldots \ldots \ldots$

Gameron, Duncan :

Le Fonds monétaire international, la réforme monétaire et le Tiers-Monde

Ghateau, Jean-Pierre :

Une analyse économétrique de la demande et de l'offre de dépôts des sociétés de crédit populaire : le cas des Caisses populaires 
Cousineau, Jean-Michel :

La mobilité interprovinciale de la main-d'œuvre au Canada: le cas de l'Ontario, de la Nouvelle-Ecosse et du Nouveau-Brunswick

Daubigney, Jean-Pierre :

La théorie des groupes non compétitifs

Decaluwé, Bernard :

Quelques enseignements récents de la réforme du système monétaire international

Dehem, Roger :

L'économiste et l'autodétermination du citoyen $\ldots \ldots \ldots \ldots \ldots$

Drèze, Jacques $\mathrm{H}$. :

La prise de décision en situation d'incertitude

Duguay, Pierre :

Bref aperçu d'un modèle à forme réduite de prévision de la dépense

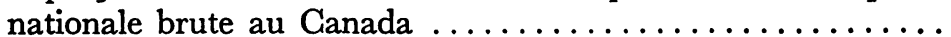

Dussault, François ; Lacroix, Robert :

La grève : ses facteurs déterminants et son effet sur les hausses de salaire. Une synthèse critique

Fleurent, Diane (voir : Aubry, Jean-Pierre)

Freedman, Gharles :

Taux d'intérêt à long terme, martingales, et marchés efficients .... 360

Gauthier, Gilles :

A propos de l'union monétaire anglo-irlandaise

Hanel, Petr :

L'innovation et le modèle du commerce néo-technologique dans l'espace des caractéristiques de Lancaster .............

Julien, Pierre-André :

Incidence de la politique scientifique fédérale sur l'économie québécoise

Kihlstrom, Richard (voir : Boyer, Marcel)

LAGROIX, Robert (voir : Dussault, François)

Laffont, Jean-Jacques (voir : Boyer, Marcel)

Lelart, Michel :

La mise en place du système monétaire européen $\ldots \ldots \ldots \ldots 568$

LEPORE, G. ; VelK, T. :

La perte de consommation canadienne attribuable à l'absence d'union douanière avec les Etats-Unis

LEROY, VÉLY :

Un résumé des lignes de force du système monétaire international actuel 
Marghon, MaURice-N. :

Le taux de croissance de l'offre de monnaie et arbitrage entre le taux d'inflation et le taux de chômage au Canada ..........

Morin, Normand ; Rabeau, Yves :

Résultats de scénarios à l'aide d'un modèle à moyen terme de l'économie du Québec ..............................

Pelletier, Gérard :

Marx dans un nouveau cadre welfariste

Phaneuf, Louis :

Offre globale en économie ouverte, courbe de Phillips et détermination du taux de chômage naturel : une reformulation théo-

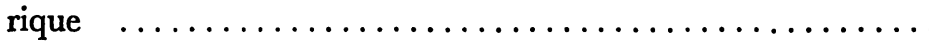

Pouyez, Ghristian (voir : Bouchard, Gérard)

RabeaU, Yves (voir : Morin, Normand)

Roy, Pauline (voir : Abgrall, Jean-François)

Roy, Raymond (voir : Bouchard, Gérard)

Saint-Germain, Maurice (voir : Gameron, Duncan)

Salvas-Bronsard, Lise (voir : Bronsard, Camille)

SÉGuin-Dulude, Louise :

Analyse de la politique commerciale canadienne : rétrospective et

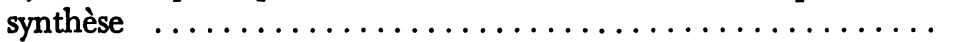

ThÉORET, RAYMond :

L'impact de la Banque du Ganada sur la disponibilité du crédit bancaire : 1967-1976

Vaillancourt, François :

Les attributs linguistiques et la détermination du revenu des hommes au Québec en 1971 : les groupes d'âge et d'éducation .

VAN DAM, ANDré :

Adieu, Bretton Woods ! .......................... 267

VeLK, T. (voir : Lepore, G.) 